\title{
Comparison of pyogenic granuloma excision using scalpel, electrosurgery and diode laser
}

\author{
Madhuri A. Sawai ${ }^{1{ }^{1 *}, Z^{2}}$ Zeba Jafri ${ }^{2}$, Nishat Sultan ${ }^{3}$, Anika Daing ${ }^{4}$, Kirti Chawla ${ }^{5}$ \\ ${ }^{\mathbf{1}}$ Associate Professor, ${ }^{2-5}$ Assistant Professor, Dept. of Periodontology, Jamia Millia Islamia, New Delhi, India \\ *Corresponding Author: \\ Email: msawai@jmi.ac.in
}

\begin{abstract}
Oral pyogenic granulomas, a common clinical condition, occurring in all age groups, and is seen frequently in females around the second decade of their life. It occurs as a sessile or pedunculated growth varies in color from red to purple. It is frequently seen on the marginal gingiva especially in the maxillary arch. Anterior teeth are more frequently affected then posteriors. They are commonly seen on the facial aspect and usually do not show radiologic findings. The treatment is surgical excision which was usually done with scalpel blade. However, with recent technological advances, excision can be done using electrosurgery and diode lasers. In the present case report, excision of pyogenic granuloma is done using scalpel, electrosurgery and diode laser.
\end{abstract}

Keywords: Soft tissue lasers, Diode laser, Electrosurgery, Scalpel, Pyogenic granuloma.

\section{Introduction}

Pyogenic granuloma is a common benign mucocutaneous lesion. This term is a misnomer as the lesion is neither granulomatous nor it contains pus. It was originally described in 1897 by two French surgeons, Antonin Poncet and Dor. ${ }^{1}$ It is most commonly seen on the marginal gingiva, but lesions have been reported on palate, buccal mucosa, tongue, and lips. Extraorally, it is observed to occur on the skin of face, neck, upper and lower extremities, and mucous membrane of nose and eyelids.

These benign overgrowths commonly known as "epulides" have multifactorial etiology: irritative factors (defective dental fillings, ill fitting dentures, poor oral hygiene, smoking, chewing tobacco, gingivitis and periodontal disease), hormonal disturbances (during pregnancy) or blood dyscrasias (anemias, etc).

The treatment of epulide is to remove the etiological factor with surgical excision. As it is a non-neoplastic growth, excisional therapy is the treatment of choice but some alternative approaches such as cryosurgery, excision by Nd:YAG Laser, flash lamp pulsed dye laser, injection of corticosteroid or ethanol, and sodium tetradecyl sulfate sclerotherapy have been reported to be effective. ${ }^{1}$

The conventional mode of surgical excision of epulides is with the use of a scalpel blade.,3

However, in dentistry, since 1928 electrosurgery has been used for soft tissue procedures like gingivectomy, gingivoplasty, soft tissue growth excision, crown lengthening, etc. ${ }^{4}$ It has a coagulative effect and hence provides a clear, bloodless view of the operating field. It is available with multiple tips which are angulated and hence cuts can be easily made. ${ }^{4}$

Recently, diode laser has been introduced for soft tissue excision procedures like operculectomy, frenectomy and gingivectomy, etc. They have been useful as it makes the procedure bloodless, with less pain perception and better control as its advantages. ${ }^{5}$

The aim of the present article is to compare the surgical excision of pyogenic granulomas by three different methods: scalpel, electrosurgery and diode laser.

\section{Case report 1}

A 16 year old male patient reported to the Department of Periodontology, Faculty of Dentistry, Jamia Millia Islamia, with the chief complaint of swelling on the gums since last 8-10 months. The swelling appeared as a small, round growth which gradually increased in size to achieve the present dimensions in the past 6-7 months. There was no associated pain or bleeding from the lesion. On intraoral examination, the growth was soft, oval with smooth surface extending from tooth \#24 to tooth \#20 on the lingual aspect of the mandibular arch. It was a pedunculated lesion attached to the interdental papillary gingiva in between tooth \#21 and \#22. The size was approximately $1.5 \mathrm{~cm} \mathrm{X} 1 \mathrm{~cm} \mathrm{X} 1 \mathrm{~cm}$. Medical history was not relevant. [Fig. 1] Radiological examination did not reveal any bony involvement. Phase I therapy was carried out after taking due informed consent. Excision of the pyogenic granuloma was conducted using scalpel blade under local anesthesia with adrenaline. Hemostasis was achieved using pressure pack and then the area was covered with periodontal dressing. Post-operative instructions were given. The biopsy sample was sent for histopathology which suggested it to be pyogenic granuloma. The stained section showed orthokeratinized stratified squamous epithelium with a prominent granular layer. The underlying fibrous connective tissue shows presence of numerous dilated and engorged blood vessels of varying caliber with prominent endothelial cell proliferation. Presence of chronic inflammatory infiltrate is also noted. The patient was subsequently seen after 1 
week, 2 weeks post-surgically. [Fig. 2] Healing was satisfactory. However, patient complained of pain for the initial 3 days after the surgery for which he had to take analgesics.

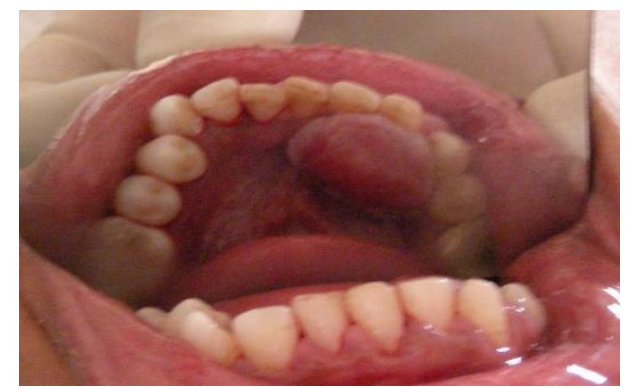

Fig.1: Shows the pyogenic granuloma in relation to tooth \#21 and \#22

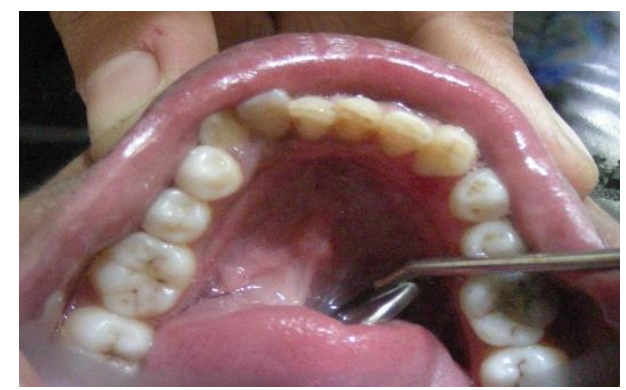

Fig. 2: Two week postoperative result

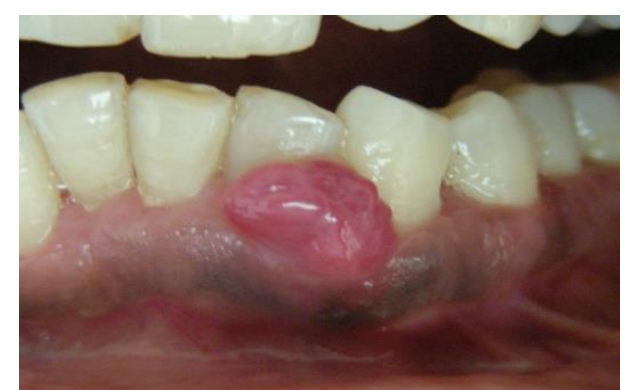

Fig. 3: Swelling on the labial aspect of tooth $\# 22$ and $\# 23$

\section{Case report 2}

A male patient, aged 35 years, reported to the Department of Periodontology, Faculty of Dentistry, Jamia Millia Islamia, with the chief complaint of swelling on the gums in relation to the lower front teeth since the past $1-2$ months. The swelling was erythematous, nodular, approximately $0.5 \mathrm{~cm} \mathrm{X} 1 \mathrm{~cm} \mathrm{X} 1$ $\mathrm{cm}$ on the labial aspect of tooth \#22 and \#23. It did not bleed and was soft in consistency. [Fig. 3] Patient's medical history was inconclusive. He was explained regarding the excision of the pyogenic granuloma lesion and informed consent obtained. After phase I therapy was completed, the lesion was excised using fine wire electrode of electrosurgery unit [BONART ART- E1] in the cutting mode under local anesthesia with adrenaline. [Fig. 4] Hemostasis was achieved using the heavy ball electrosurgery tip in coagulation mode. Periodontal pack was placed and post-operative instructions were given. The patient was evaluated after 1 week and 2 weeks. Healing was fairly good and a layer of slough was seen at the end of first week. [Fig. 5] Patient complained of mild discomfort for 1-2 days post-surgery. The biopsy was sent for histopathological examination which suggested it to be pyogenic granuloma as it showed parakeratinized stratified squamous epithelium. The underlying fibrous connective tissue showed numerous dilated vessels mild chronic inflammatory infiltrate.

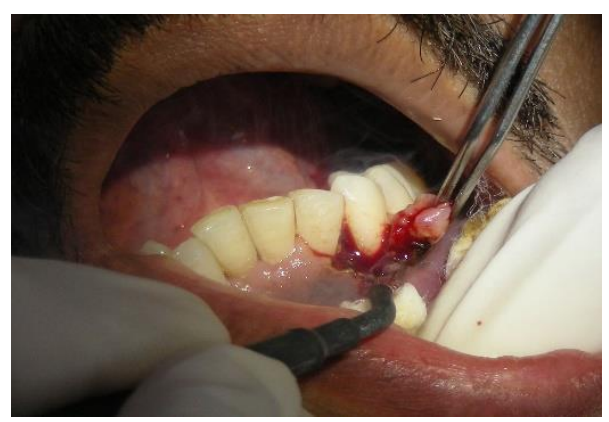

Fig. 4: Excision of the lesion done using electrosurgery

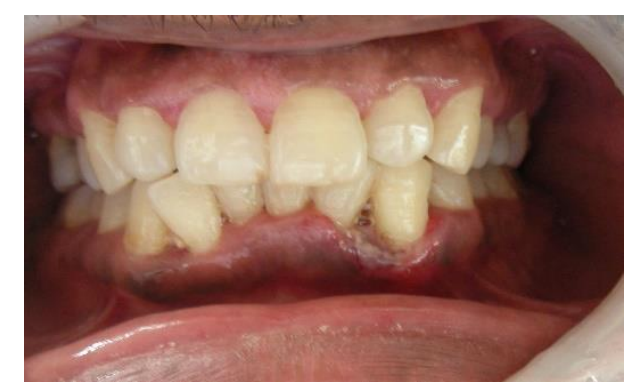

Fig. 5: One week postoperative result

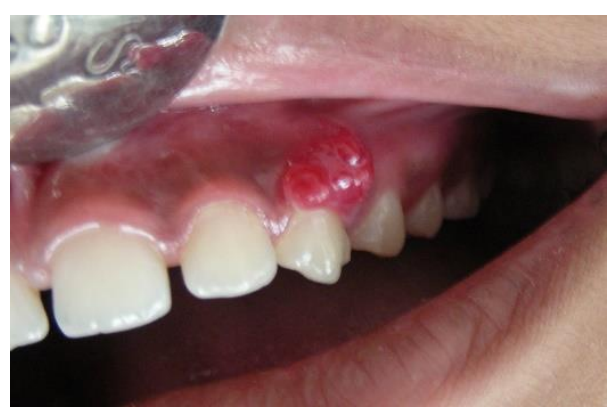

Fig. 6: Soft tissue overgrowth in respect to tooth \#11

\section{Case report 3}

A 14 year old female patient reported to the Department of Periodontology, Faculty of Dentistry, Jamia Millia Islamia, with the chief complaint of swelling in relation to upper left anterior tooth region since the past 5-6 months. The swelling gradually increased in size and was not associated with pain. On intraoral examination, the swelling was soft, fluctuant, approximately $0.5 \mathrm{~cm} \mathrm{X} 1 \mathrm{~cm} \mathrm{X} 1 \mathrm{~cm}$, sessile lesion in respect to facial aspect of tooth \#11. [Fig. 6] The lesion showed pitting on pressure which predicted bleeding 
during excision and hence was decided to excise it using diode laser. The patient underwent oral prophylaxis and routine blood investigations were done which did not show any abnormalities. The excision was carried out under local anesthesia with adrenaline using $810 \mathrm{~nm}$ diode laser [DENLASE] in a pulsed mode at the setting of $5.0 \mathrm{~W}$. There was minimal bleeding and pain during the procedure. The surgical site showed thin connective tissue over the alveolar bone and periosteum after the excision. [Fig. 7] The area was cleaned and periodontal dressing was placed. The biopsy was sent for histopathology and the patient was evaluated after 7 days. The area showed mild redness. [Fig. 8] However, the patient did not complain of any pain in the postoperative period. The histopathology reported the lesion to be pyogenic granuloma. The hematoxilin and Eosin stained section of soft tissue showed presence of nonkeratinized atrophic stratified squamous epithelium. The underlying connective tissue shows presence of numerous blood vessels with proliferating endothelial cells. Mixed inflammatory infiltrate was noted.

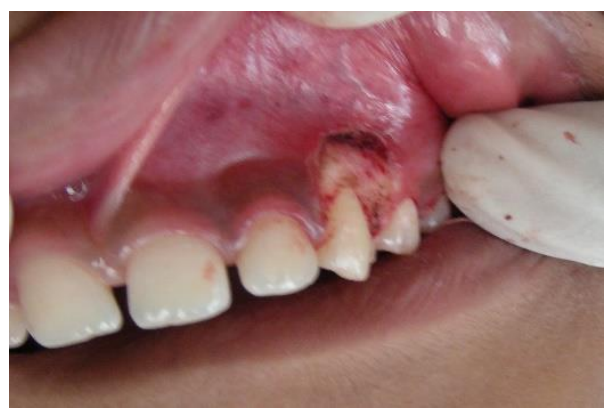

Fig. 7: Excision done using 810nm Diode laser

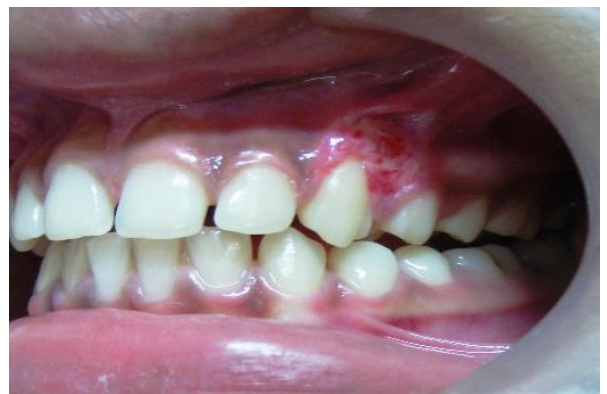

Fig. 8: One week postoperative result

\section{Discussion}

Pyogenic granuloma is a well known and commonly occurring oral inflammatory hyperplastic condition. The etiological factors include chronic low-grade irritation, ${ }^{6}$ trauma, hormonal factors ${ }^{[7]}$ and certain drugs. Poor oral hygiene, local irritants and foreign material in the gingiva act as precipitating factors for the occurrence of pyogenic granulomas. ${ }^{8}$

Oral pyogenic granulomas occur more frequently in females than males, in the second decade which could be due to increase in the levels of hormones. ${ }^{9}$ They occur in all age groups including children and adults. Oral pyogenic granulomas occur on gingiva in $75 \%$ of cases. They are more commonly seen on the anterior attached gingiva of the maxilla, more on the labial aspect than on the lingual side. ${ }^{6}$ They occur as a sessile or pedunculated growth which is usually covered with erythematous papules or is ulcerated and covered with fibrous membrane. ${ }^{6}$ The color of the lesion can vary from red to pink depending of the vascularity of the growth. The lesion is usually slow growing and painless but may show rapid growth spurts. Radiographically, no underlying bony changes are seen. However, in long standing cases some alveolar bone resorption can be evident. ${ }^{10}$

The differential diagnosis of pyogenic granuloma includes peripheral giant cell granuloma, peripheral ossifying fibroma, hemangioma, kaposi's sarcoma, bacillary angiomatosis, non- hodgkin's lymphoma, angiosarcoma, and metastatic cancer. ${ }^{11}$ Peripheral giant cell granuloma is clinically similar to PG, but presence of bone resorption and appearance of the multinucleated giant cell are differentiating features. ${ }^{12}$ Peripheral ossifying fibroma can be distinguished by the consistency, texture, and the lighter color. ${ }^{6}$ Hemangioma is a developmental disorder, commonly seen on the tongue. It can be multinodular and bluish red in colour. They can be easily diagnosed by a chairside "Diascopy" procedure. ${ }^{13}$ Kaposi's sarcoma and bacillary angiomatosis can be differentiated as they are AIDS related and show specific histopathological picture. ${ }^{1} \mathrm{~A}$ gingival non-Hodgkin's lymphoma is usually found to be an asymptomatic gingival enlargement or mass resembling a pyogenic granuloma which requires histopathological confirmation for diagnosis. ${ }^{1}$ Pyogenic granuloma can be diffentiated from angiosarcoma by its lobular growth pattern and histological picture showing well-formed vessels and cytologically bland endothelial cells. ${ }^{14}$ Metastatic tumors can also show clinical resemblance to pyogenic granuloma. However, the microscopic appearance will differentiate it as the tumor of origin. ${ }^{6}$

Treatment of pyogenic granuloma includes removal of irritants and any other etiology followed by surgical excision. In the current case series, three different modalities for excision: scalpel, electrosurgery and diode laser were used. When comparing the handling properties between the three modes of treatments, it was observed that scalpel had ease of handling. The incisions were precise with well - defined margins. There was no lateral tissue damage and was economical. However, there was need of anesthesia, bleeding during procedure which reduced the visibility and increased time required for the procedure.

The advantage of electrosurgery was that the electrode cut the tissues with ease, hemostasis was immediate and the tip was self-disinfecting. However, it had various disadvantages: need of anesthetic agent, burning tissue odor, low tactile sensation. However, there 
is a danger of damage to the underlying bone and it is contraindicated in patients with cardiac pacemakers.

Diode laser has various advantages compared to scalpel and electrosurgery. It requires minimal or no anesthetic. They do not produce any harmful effect on the underlying hard tissues. There is least discomfort with minimal or no bleeding. Hence, post-operative edema is less. Laser wounds have been found to contain significantly less number of myofibroblasts, ${ }^{15}$ resulting in less wound contraction and scarring, and improved healing. However, there are certain disadvantages; the cutting is slow and there is burning flesh odor.

The assessment at one week post-surgery revealed that healing was best and faster in the case where scalpel was used. It was followed by laser and lastly electrosurgery. Healing was delayed in case of diode laser and more so with electrosurgery which can be attributed to lateral heat production. Literature shows that the lateral heat damage with the use of lasers in histological sections was found to be $28.3-98 \mu \mathrm{m}^{16}$ and with the electrosurgery is $0.12-0.31 \mathrm{~mm} .{ }^{17}$

Funde et al. has reported similar results in their case report where scalpel, electrosurgery and laser was used for the treatment of drug induced gingival overgrowth. ${ }^{4}$ Karanth $\mathrm{S}$ et al. ${ }^{18}$ in a case report have showed that using $940 \mathrm{~nm}$ diode laser was useful for the treatment of pyogenic granulomas as it was bloodless, easy and comfortable to use and hence a preferable option for excision of pyogenic granulomas. Koppolu et al. ${ }^{19}$ compared the excision of lesions with diode laser and scalpel and concluded that for intraoral soft tissue surgical techniques, laser is a reasonable alternative to the scalpel as there is diminished postoperative swelling and pain with improved safety.

Thus, the conventional scalpel surgery is better when incision lines have to be precise without lateral heat damage. Diode laser and electrosurgery are beneficial in achieving hemostasis and easy to maneuver. However, they have certain demerits like delayed wound healing, lateral heat damage and burning flesh odor. Also, there is high cost to the patient and skill of the operator is an additional drawback.

\section{Conclusion}

To summarize, advanced surgical treatment modalities like diode lasers and electrosurgery have multiple advantages over the conventional surgical instruments like scalpel. However, they all have one or multiple limitations like elevated cost, less precision and delayed postoperative healing.

\section{References}

1. Jaferzadeh H, Sanadkhani M, Mohtasham M. Oral pyogenic granuloma: A review. J Oral Sci 2006;48:16775.

2. Ize-Iyamu, Idia \& Saheeb, Birch \& E Edetanlen, B. Comparing the 810nm Diode Laser with Conventional Surgery in Orthodontic Soft Tissue Procedures. Ghana Med J 2013;47:107-11.
3. Fornaini C, Rocca JP, Bertrand MF, Merigo E, Nammour S, Vescovi P. Nd:YAG and diode laser in the surgical management of soft tissues related to orthodontic treatment. Photomed Laser Surg 2007;25:381-92.

4. Funde S, Baburaj MD, Pimpale SK. Comparison between Laser, Electrocautery and Scalpel in the Treatment of Drug-Induced Gingival Overgrowth: A Case Report. IJSS Case Reports \& Reviews 2015;1(10):27-30.

5. Ozcelik O, Cenk Haytac M, Kunin A, Seydaoglu G. Improved wound healing by low-level laser irradiation after gingivectomy operations: a controlled clinical pilot study. $J$ Clin Periodontol 2008;35:250-4.

6. Neville BW, Damm DD, Allen CM, Bouquot JE. Oral and Maxillofacial pathology. $2^{\text {nd }}$ ed. Philadelphia: Saunders 2002:437-95.

7. Mussalli NG, Hopps RM, Johnson NW. Oral pyogenic granuloma as a complication of pregnancy and the use of hormonal contraceptives. Int J Gynaecol Obstet 1976;14(2):187-91.

8. Gomes SR, Shakir QJ, Thaker PV, Tavadia JK. Pyogenic granulomas of the gingival: A misnomer? - A case report and review of literature. J Ind Soc Periodontol 2013;17: 514-9.

9. Ojanotko-Harri AO, Harri MP, Hurttia HM, Sewón LA. Altered tissue metabolism of progesterone in pregnancy gingivitis and granuloma. J Clin Periodontol 1991;18:2626.

10. Angelopoulos AP. Pyogenic granuloma of the oral cavity: Statistical analysis of its clinical features. J Oral Surg 1971;29:840-7.

11. Calonje E, Wilson Jones E. Vascular tumours: Tumours and tumour like conditions of blood, vessels and lymphatics. In: Elder D, Elenitsas R, Jaworsky C, Johnson BJ, editors. Lever's Histopathology of the Skin. $8^{\text {th }}$ ed. Philadelphia: Lippincott-Raven 1997:895.

12. Regezi JA, Sciubba JJ, Jordan RC. Oral Pathology and CLINICAL Pathological Considerations. $4^{\text {th }}$ ed. Philadelphia: W B Saunders 2003:115-6.

13. Greenberg MS, Glick M. Burket's Oral Medicine. Diagnosis and Treatment. $11^{\text {th }}$ ed. McGraw Hill 2003:1304.

14. Pilch BZ. Head and Neck Surgical Pathology. Philadelphia: Lippincott Wlliams \& Wilkins 2000:389-90.

15. Zeinoun T, Nammour S, Dourov N, Aftimos G, Loumanen M. Myofibroblasts in healing laser excision wounds. Laser Surg Med 2001;28:74-9.

16. Goharkhay, K., Moritz, A., Wilder-Smith, P., Schoop, U., Kluger, W., Jakolitsch, S. and Sperr, W. Effects on oral soft tissue produced by a diode laser in vitro. Lasers Surg Med 1999;25:401-6.

17. Noble WH, McClatchey KD, Douglass GD. A histologic comparison of effects of electrosurgical resection using different electrodes. J Prosthet Dent 1976;35:575-9.

18. Karanth S, Shetty D, Hemanth M, Varma M, Varma L, Fernandes B. Treatment of pyogenic granuloma using a 940nm Diode laser. Sch J Dent Sci 2015;2(1):54-7.

19. Koppolu P, Mishra A, Kalakonda B, Swapna LM, Bagalkoikar A, Macha D. Fibroepithelial polyp excision with laser and scalpel: A comparative evaluation. Int J Curr Microbiol App Sci 2014;3(8):1057-62. 